\title{
Peak Demand Management in Micro Hydro using Battery Bank
}

Pradeep Paudel and Shailesh Wasti

Abstract: Millions of Nepali inhabit in a far-flung hamlet of Nepal, where the extension of national grid is unlikely even in the new future. Isolated Micro-hydro power plants are extensively used in these areas. This paper addresses the problem of deficient electricity during peak period in existing conventional micro-hydro plants by the introduction of battery storage in the plant. Micro-hydro plant with battery bank storages surplus power, which would be wasted in case of conventional micro-hydro plant, during off- peak period and supplies during peak period. The control strategies for Electronic Load Controller (ELC), three - phase ac/dc converter and buck converter are realized in Matlab Simulink environment. The simulated system was able to store surplus power into battery bank when load demand was less than power generated by Synchronous Generator (SG) and supply when the load demand was higher than generator's generation. This model can be implemented in the already existing micro-hydro plants where the load demand for a short time has increased beyond generation capacity of generator.

Keywords: Micro-hydro, ELC, battery storage, deficient electricity, SG, Nepal

\section{Introduction}

Glectricity is pre-requisite for development and Equality of life. While the developed countries take it as granted, access to electricity is a privilege in third world countries like Nepal. As of 2015, Nepal's per capita electricity consumption is 0.14 MWh while that of the United States is $12.83 \mathrm{MWh}$ (International Energy Agency, n.d.). This startling gap has exacerbated poverty in an already impoverished life of country people. Seventy-eight per cent of total households rely on traditional biomass for cooking (CBS, NepalLivingStandardSurvey, 2011) and more than eighty per cent of the country's households are in rural areas (CBS, 2012).

Electricity generated from non-renewable sources cause climate change and affects the human lives, especially people under poverty line. Renewable sources of energy like hydro, solar and wind are the most soughtafter resources these days. Given the intermittent nature of solar and wind energy, hydropower remains the most consistent renewable source of energy. Nepal has hydro potential of 83,000 MW (Shrestha, 1966). Steep mountainous terrain and continuous flow in more than 6000 rivers/rivulets makes hydropower widely available throughout the hilly region of Nepal (Sharma \& Awal, 2013).

It needs massive amount of investment to tap the enormous potential of hydropower. Besides, the diversely scattered localities in the complex terrain of hills and mountains made the extension of national grid prohibitively expensive. Micro hydro with Electronic Load Controller (ELC) is reliable and cost-friendly to the people living in rural areas as water current doesn't cost and technology employed is simple to install, operate and maintain. The peak demand may increase after a certain time span as the use of electricity is not limited to lighting proposes. In order to manage peak demand, the plant is left with two options - either installs a new generator or adds another source to support for a short time of peak. As the installation of new generator is expensive, battery bank is best suited for peak demand management. Battery can be charged during off peak from the surplus power generated from the micro hydro and can be used during the peak time.

\section{Proposed System}

The conventional Micro Hydro Plant (MHP) consists of a synchronous generator and dump loads. Our proposed scheme aims to add storage battery scheme to the existing MHP for peak demand management. The system consists of a Synchronous Generator (SG) of capacity $60 \mathrm{kVA}$, dump loads and a battery bank. The consumer load is expected to vary from zero to seventy kilowatts. The capacity of dump load is chosen in such a way that it can dissipate maximum power output of MHP. The capacity of storage battery chosen-200 $\mathrm{Ah}, 600 \mathrm{~V}$ lithium ion - is enough to provide $10 \mathrm{~kW}$ of deficient power for 4 hours without exceeding fifty per cent depth of discharge. A bidirectional three phase $\mathrm{ac} / \mathrm{dc}$ convertor is used to convert power in a suitable form. Battery is charged through buck convertor which regulates charging according to the State of Charge (SOC).

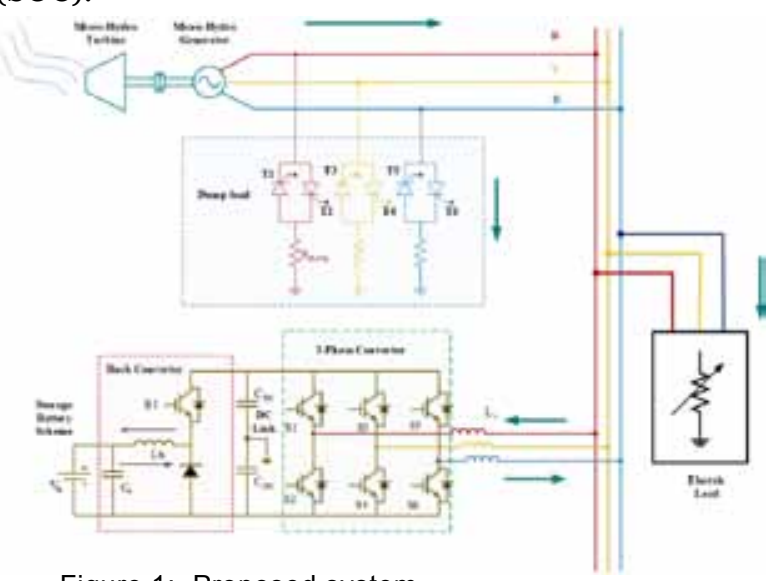

Figure 1: Proposed system 
The load is assumed to draw active power only. Sinusoidal voltage waveforms are chopped when the antiparallelly connected thyristors are fired. Due to chopping, dump load though resistive in nature draws lagging current. The synchronous generator provides the reactive power demanded by dump load. The analysis of reactive power is not carried out in this paper.

The parameters used during modelling of the system are summarized in the following table 1.

\begin{tabular}{|c|c|c|}
\hline Symbol & Value & Description \\
\hline $\mathrm{C}_{\mathrm{b}}$ & $10 \mathrm{mF}$ & Battery Side Capacitor \\
\hline $\mathrm{L}_{\mathrm{b}}$ & $20 \mathrm{mH}$ & Buck Inductor \\
\hline $\mathrm{C}_{\mathrm{dc}}$ & $10 \mathrm{mF}$ & DC link Capacitor \\
\hline $\mathrm{L}_{1 \mathrm{a}}$ & $10 \mathrm{mH}$ & Coupling Inductor \\
\hline $\mathrm{V}_{\mathrm{B}}$ & $600 \mathrm{~V}$ & Nominal Battery Voltage \\
\hline $\mathrm{R}_{\mathrm{dump}}$ & $2.22 \mathrm{ohm}$ & Dump load Resistor \\
\hline Pgen & $60 \mathrm{~kW}$ & Capacity of SG \\
\hline
\end{tabular}

Table 1: System Parameter

\section{Modes of Operation}

The generator should feed the power on the priority basis - first to the consumer load then to the battery depending on the SOC and finally to the dump load. Constant current charging (40A) and constant voltage charging $(615 \mathrm{~V})$ methods are used for $\mathrm{SOC}<80 \%$ and SOC $>80 \%$ respectively. Power demanded by battery is the power to be consumed by battery during these charging methods.

Excess power $=$ Generated power - Load demand Deficient power $=$ Load Demand - Generated power

Mode 1: Excess Power > Power Demanded by Battery Here surplus power, power left after consumed by load and battery system, is dissipated to dump load.

Mode 2: Excess Power < Power Demanded by Battery In this loading condition, total excess power is used to charge battery without dissipating to dump load.

Mode 3: Load > Power Generation

In this loading condition, battery system supplies deficient power to load. Here, no power is dissipated to dump load.

\section{Controllers}

\section{Electronic Load Controller}

The frequency of EMF generated changes whenever the consumer load varies; the frequency decreases when the load increases and increases when the load decreases. The error signal obtained by comparing actual frequency and reference frequency $(50 \mathrm{~Hz}$ in this case) is passed through PI controller which then generates firing angle. The pulse generator generates pulse to fire thyristors which are in series with ballast load at given firing angle. RMS value of voltage across ballast load is controlled by chopping 3-phase voltage signal.

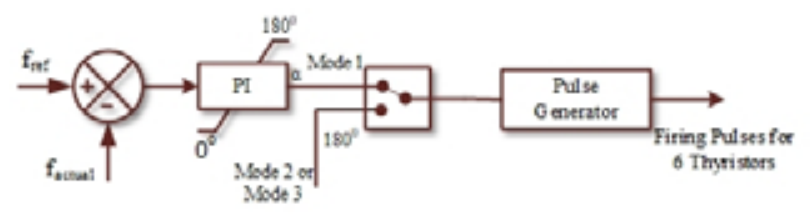

Figure 2: Electronic Load Controller

The value of resistance of dump load is chosen such that it can dissipate total power generated by MHP when no power is demanded by consumer and battery together.

The resistance per phase of dumb load is given by,

$\mathrm{R}_{\text {Dump }}=\frac{\mathrm{V}_{\mathrm{s}}^{2}}{\mathrm{~K} \times \mathrm{P}_{\mathrm{gen}}}$

Where, Vs= line voltage

$\mathrm{P}_{\text {gen }}=$ Power generated by MHP

$\mathrm{K}=$ secondary load multiplication factor and generally considered as 1.2 (Gyawali, Paudel, \& Subedi, 2015).

Power dissipated to dump load at any firing angle alpha $(\alpha)$ is given by,

$\mathrm{P}_{\text {Dump }}=\frac{\mathrm{V}_{\mathrm{s}}^{2}}{\mathrm{R}_{\text {Dump }}}\left[\frac{1}{\pi}(\pi-\alpha)+\frac{\operatorname{Sin}(2 \alpha)}{2}\right]$

At mode 2 and mode 3 of operation, no power is dissipated on ballast load. This is done by applying direct 1800 firing angle to thyristors.

\section{Controller for 3-phase dc/ac Convertor}

In this paper, we use the hysteresis band current control method to control the power flow through ac/dc convertor. The Hysteresis Band Pulse with Modulated (HBPWM) convertor is basically an instantaneous feedback current control method of PWM where actual current continuously tracks the reference current within predefined hysteresis band limit (Ranganadh, Prasad, \& Sreedhar, 2013) Fig 3 shows the control block diagram of HBPWM.

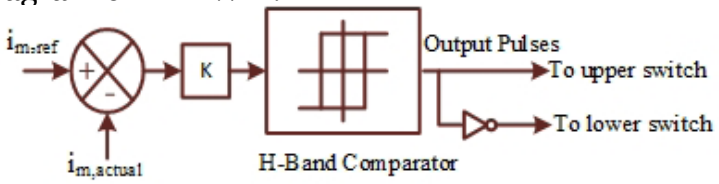

Figure 3: H-Band Comparator 
The control circuit generates the 3-phase reference current of desired magnitude and frequency and is compared with actual phase current wave. H-Band comparator receives error signal obtained after scaling by certain factor and gives the output pulse according to the following rule (Ranganadh, Prasad, \& Sreedhar, 2013).

If, $\left|i_{m, r e f}-i_{m}\right|<e$, keeps the output pulse in the same state $i_{m, r e f}-i_{m}>$ e, let output pulse $=1$ (high)

$i_{m, r e f}-i_{m}<-e$, let output pulse $=0$ (low)

Where $\mathrm{m}=\mathrm{a}, \mathrm{b}, \mathrm{c}$ phases and $\mathrm{e}$ is the hysteresis band.

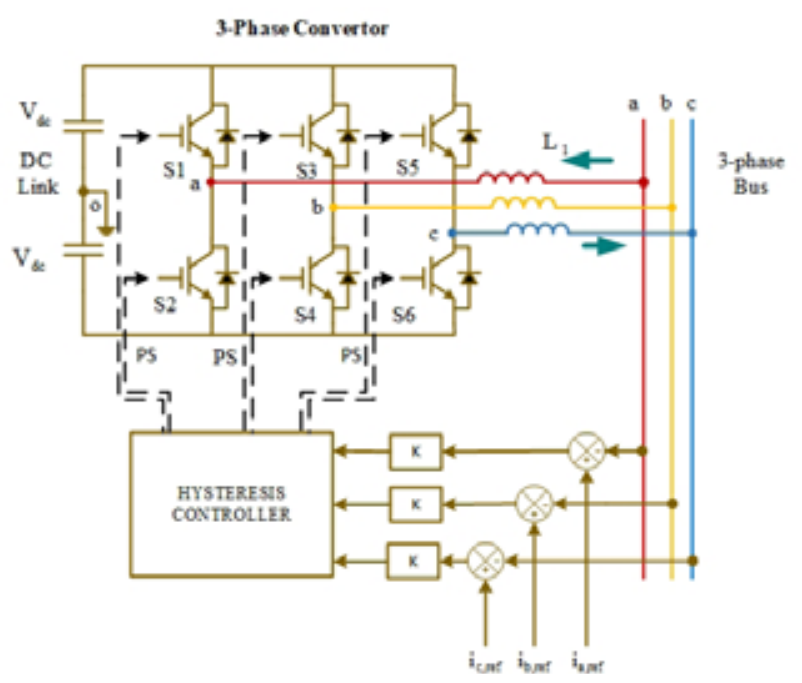

Figure 4: HBPWM current control method

The HBPWM invertor control method is shown in Fig 4. If current exceeds prescribed hysteresis band i.e., $i_{m, r e f}-i_{m}<-e$, the H-Band comparator generates low (o) output pulse. The gate drive of upper switch of convertor gets low pulse which turns off the switch. At the same time gate drive of lower switch gets high (1) pulse which turns on the switch. As a result, output voltage transition occurs from $+\mathrm{V}_{\mathrm{dc}}$ to $-\mathrm{V}_{\mathrm{dc}}$ and current starts to decay. As current crosses the lower band limit i.e., $\mathrm{i}_{\mathrm{m}, \mathrm{ref}}-\mathrm{i}_{\mathrm{m}}>\mathrm{e}$, the H-Band comparator generates high (1) output pulse. The gate drive of upper switch gets high pulse and simultaneously lower switch gets low pulse. As a result, output voltage changes from $-\mathrm{V}_{\mathrm{dc}}$ to $+\mathrm{V}_{\mathrm{dc}}$ and current starts to rise. The actual current thus tracks the reference current within prescribed hysteresis band by back and forth switching of upper and lower switches. Fig 5 shows the operation of $\mathrm{H}$-Band convertor.

The algorithm for this scheme is,

$\mathrm{i}_{\mathrm{m}, \mathrm{ref}}(\mathrm{t})=\mathrm{I}_{\mathrm{m}, \mathrm{ref}} \sin (\mathrm{wt})$

Upper band, $i_{u}=i_{m, r e f}(t)+\Delta i$

Lower band, $\mathrm{i}_{1}=\mathrm{i}_{\mathrm{m}, \mathrm{ref}}(\mathrm{t})-\Delta \mathrm{i}$

Where, $\Delta \mathrm{i}=$ hysteresis band limit

If $\mathrm{i}_{\mathrm{m}}>\mathrm{i}_{\mathrm{u}}, \mathrm{V}_{\mathrm{mo}}=-\mathrm{V}_{\mathrm{dc}}$

If $\mathrm{i}_{\mathrm{m}}<\mathrm{i}_{1}, \mathrm{~V}_{\mathrm{mo}}=+\mathrm{V}_{\mathrm{dc}}$

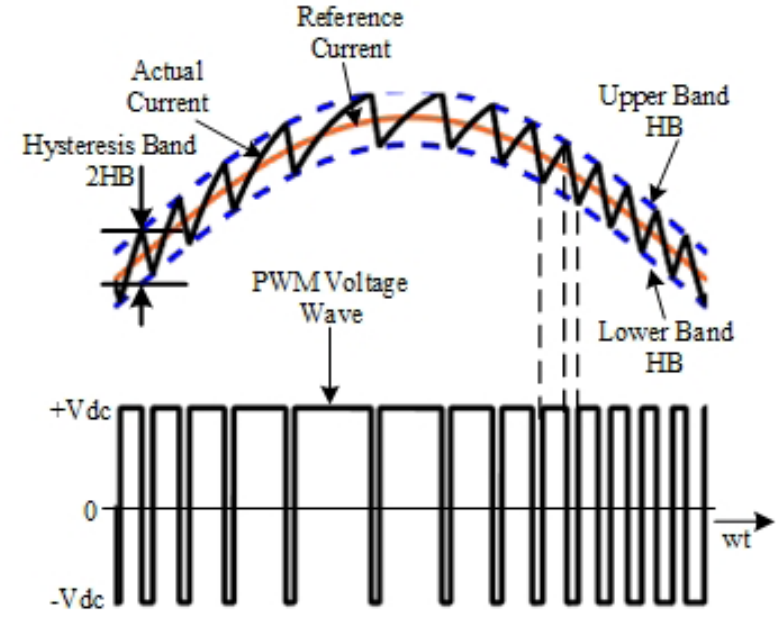

Figure 5: Principle of Hysteresis Band current control

\section{Reference Current Generation}

$\mathrm{AC} / \mathrm{DC}$ convertor draws or supplies power equivalent of 3-phase reference current as convertor continuously follows reference current. The following figure shows the reference current generation circuit.

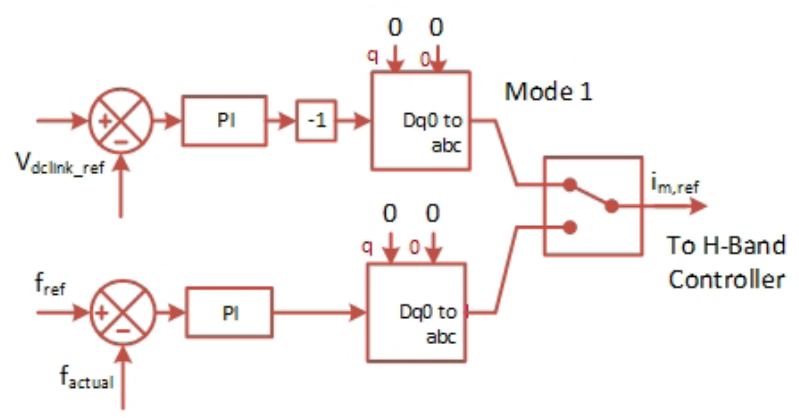

Figure 6: Control diagram for reference current generation

\section{Mode 1}

As battery draws varying power through buck convertor, dc link voltage tends to fluctuate. The error signal obtained by comparing actual dc link voltage with reference dc link voltage $(800 \mathrm{~V})$ passes through PI controller which gives reference d-axis current. Reference $d$-axis current is converted to equivalent abc frame to get 3-phase reference currents. As we are concerned only with active power, $q$ and o components are kept zero.

If $d$-axis current is positive, abc reference currents are in phase with generated voltages. Thus, power flow occurs from dc side to ac side. And if d-axis current is negative, abc reference current are out of phase with generated voltages. At this condition, power flows from ac side to dc side. To draw power from ac side to dc side, we need negative d-axis current which is obtained by multiplying output of PI controller by -1 as shown in Fig 6.

\section{Mode 2}

$\mathrm{AC} / \mathrm{DC}$ convertor draws excess power to maintain 
frequency at reference value $(50 \mathrm{~Hz})$. DC voltage is not controlled here thus it drops to value just above battery voltage. Frequency fluctuates with the change in consumer load. The error signal - difference of reference frequency and actual frequency - passed through PI controller gives reference d-axis current which is converted to abc frame to obtain 3-phase reference current.

\section{Mode 3}

The control scheme here is same as that of mode 2. When the decrease in frequency is detected, PI controller generates positive d-axis reference current. The abc reference current is in phase with generator voltage. Thus, the power flows from dc side to load. The ac/dc convertor supplies deficient power to power demand and maintains frequency at reference value.

Let, $\mathrm{I}_{\mathrm{m}}$ be the reference $\mathrm{d}$-axis current obtained from PI controller. After dqo to abc transformation, obtained 3 phase reference current are,

$\mathrm{i}_{\mathrm{a}}=\mathrm{I}_{\mathrm{m}} \sin (\mathrm{wt})$

$\mathrm{i}_{\mathrm{b}}=\mathrm{I}_{\mathrm{m}} \sin (\mathrm{wt}-120)$

$i_{c}=I_{m} \sin (w t+120)$

And Power through ac/dc convertor is,

$$
P_{a c / d e}=\sqrt{\frac{3}{2}} \times V_{t} \times I_{m}
$$

Where, Vs= Line voltage across generator

\section{Controller for DC/DC convertor}

Storage battery cannot be charged at an arbitrarily high rate. Internal resistance of battery produces heat and the excessive temperature rise may lead to degradation of its capacity or even death. Also, recharging at a very slow rate increases the charging duration which is also undesirable as energy stored may be insufficient to reuse after finite duration of time. At lower SOC, battery can be recharged at relatively higher rate than higher SOC. Continuous recharging with same current even after full charge also leads to degradation of its capacity. Thus, at this state, slow rate charging, sufficient only to overcome self-discharging, is welcomed. Here, buck convertor controls the power flowing to battery to safely charge it. Controller for buck convertor is shown in Fig 7. (Abusara \& Guerrero, 2014).

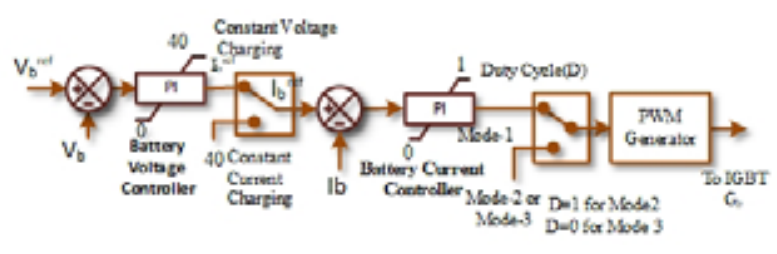

Figure 7: Controller for DC/DC convertor

\section{Mode 1:}

For $\mathrm{SOC}<80 \%$, constant current charging method is employed in which battery draws almost constant power. And for SOC $>80 \%$, constant voltage charging method is deployed. For this charging scheme, current drawn by battery continuously decreases as SOC increases and becomes zero at fully charged state. Here battery draws reduced power at higher SOC.

For constant current charging, PI controller gives duty cycles when error signal - difference of reference current (40A) and actual current - is passed through it. Gate signal generator generates PWM pulses of respective duty cycle which is passed to the gate drive of buck IGBT that limits current to battery at reference value.

For constant voltage charging, PI controller generates reference current when error signal difference of reference voltage $(615 \mathrm{~V})$ and actual battery voltage - is passed through it. The inner current control loop is same as in constant current control method that generates appropriate duty cycle such that actual voltage tracks reference voltage.

\section{Mode 2 and Mode 3}

In mode 2, DC link voltage drops and settles to a value slightly above battery voltage. To charge battery with available power, buck IGBT is always kept ON providing duty cycle 1 . The arrangement works for mode 3 too. Here, as ac/dc convertor supplies power to load from dc link, battery supplies power to dc link seamlessly through diode. In this mode dc link voltage is just less than battery voltage.

\section{Mode Transition}

The mode at which system must operate depends on the surplus or deficient power and power demanded by battery. Detecting such parameters, modes are switched. For mode 1, controllers are different than mode 2 or mode 3 but controllers for mode 2 and mode 3 are same. By observing frequency and dc link voltage, mode at which system should operate is determined and controllers are switched accordingly. Following state diagram shows the algorithm for mode transition.

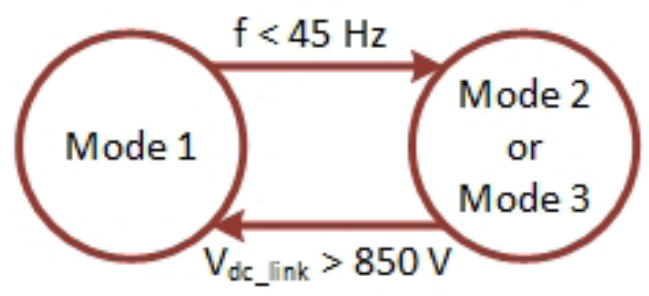

Figure 8: Figure for Mode transition 
Algorithm for mode transition:

If $\mathrm{f}>45$ and $\mathrm{V}_{\mathrm{dc} \_} \_$link $<850 \mathrm{~V}$, output remains in the same state

If $\mathrm{f}<45 \mathrm{~Hz}$, Output $=0$;

If Vdc_link $>850 \mathrm{~V}$, output $=1$;

Here, Output o means mode 2 or mode 3 of operation and output 1 means mode 1 of operation.

To understand how operation is switched to different modes following scenario is considered.

A $60 \mathrm{kw}$ generator generates power of $60 \mathrm{kw}$ and supplies power to a load of $20 \mathrm{kw}$. In this case, the system is operated in mode 1 and ac/dc convertor is operated to maintain dc link voltage at $800 \mathrm{~V}$. Battery at SOC $70 \%$ consumes power form de link at constant current of 40 A i.e., around $40600=24000 \mathrm{~W}$. Ballast load consumes excess power of $60-(20+24)=16 \mathrm{kw}$ thus maintaining frequency at $50 \mathrm{~Hz}$.

\section{What Happens If Consumer Load is Increased to $50 \mathrm{~kW}$ ?}

Battery draws $24 \mathrm{~kW}$ power from dc link and tries to continue drawing. And ac/dc convertor also tries to draw $24 \mathrm{~kW}$ power to maintain dc link voltage at $800 \mathrm{~V}$. But $60 \mathrm{~kW}$ generator cannot supply total $24+50=74 \mathrm{~kW}$ power. So, frequency starts to decrease. As frequency goes below $45 \mathrm{~Hz}$, controllers are switched to mode 2 . Here thyristors are fired at 1800 to ensure no power dissipation in dump load. Ac/dc convertor maintains frequency at $5 \mathrm{O} \mathrm{Hz}$ by supplying only excess power i.e. $60-50=10 \mathrm{~kW}$ to dc link. Buck convertor is operated at duty cycle 1 so that it consumes whole excess power coming from ac/dc convertor. During transition as battery tries to draw $24 \mathrm{~kW}$ power but ac/dc convertor cannot supply such power, dc link voltage reduces to voltage slightly greater than battery voltage.

Now, suppose load is increased to $70 \mathrm{~kW}$ from $50 \mathrm{~kW}$. Here to maintain frequency ac/dc convertor reverses the direction of power flow automatically supplying deficient power i.e. $10 \mathrm{~kW}$ to load. As there is no controller for discharging, battery voltage after some voltage drop in diode and circuit directly appears in dc link. Here dc link voltage is slightly below battery voltage.

Now let us assume the system is operated in mode 2 or mode 3 and load is decreased to $20 \mathrm{~kW}$. Here initially dump load doesn't dissipate any power. To maintain frequency, ac/dc convertor draws excess power i.e. 40 $\mathrm{kW}$ to dc link. Buck convertor is operated at duty cycle 1, so current starts to increase beyond $40 \mathrm{~A}$. As it starts to increase beyond $40 \mathrm{~A}$, buck convertor is switched to constant current mode thereby drawing only 24 $\mathrm{kW}$ power. DC link voltage starts to increase as ac/dc convertor draws greater power than power consumed by battery. As soon as de link voltage is increased beyond $850 \mathrm{~V}$, controllers are switched to mode 1 .

By this way, transition occurs from on mode to another with the change in consumer load.

\section{Simulation Result}

System is designed and simulated in the matlab environment. To check the validity of the system developed, matlab simulink model was run at different loading conditions at different SOC.

Simulation result for $\mathrm{SOC}<80 \%$ at different loading condition is given in following figures.

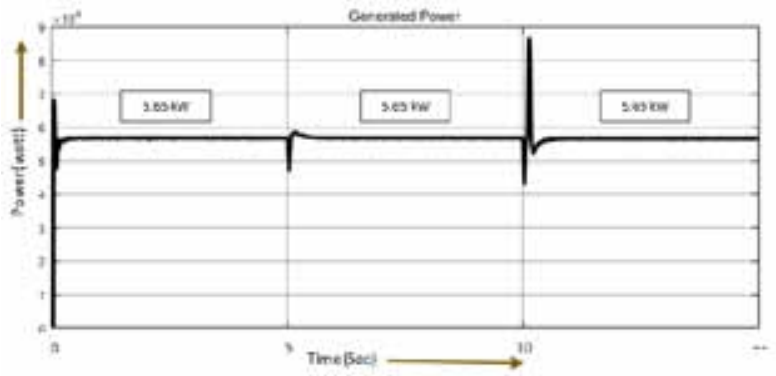

Figure 9 (a): Power Generated from Synchronous Generator

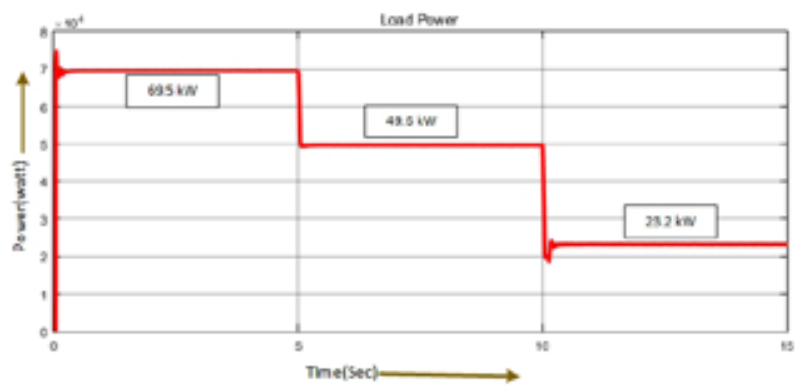

Figure 9 (b): Power consumed by load

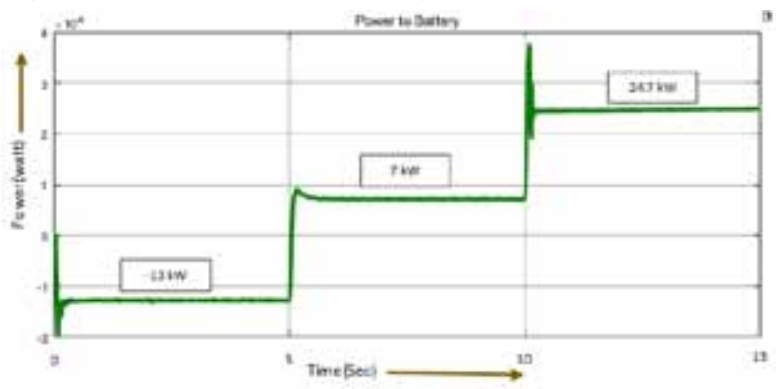

Figure 9 (c): Power consumed by Battery System

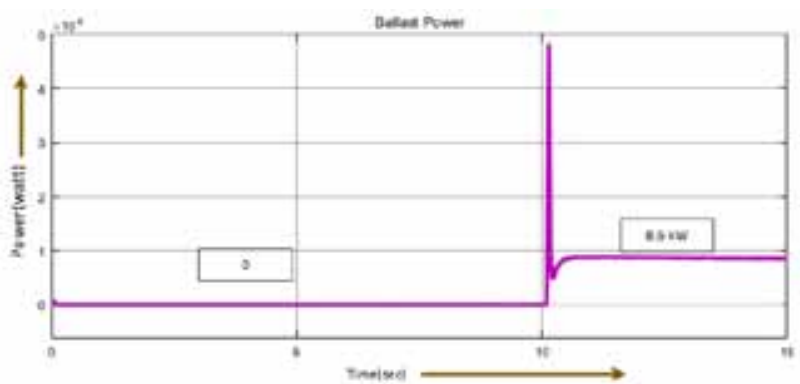

Figure 9 (d): Power dissipated on dump load 


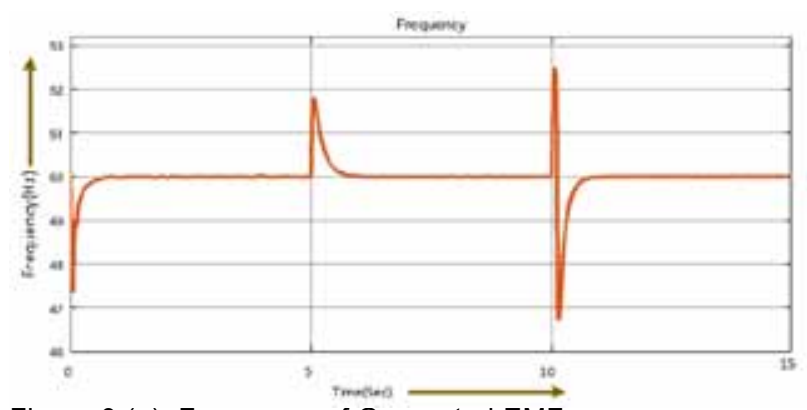

Figure 9 (e): Frequency of Generated EMF

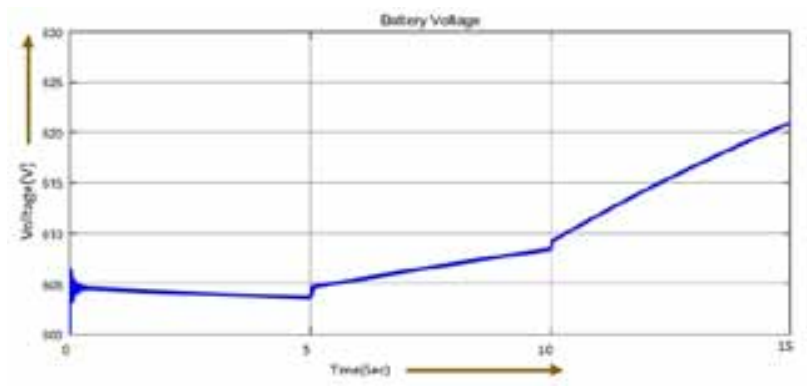

Figure 9 (f): Battery voltage

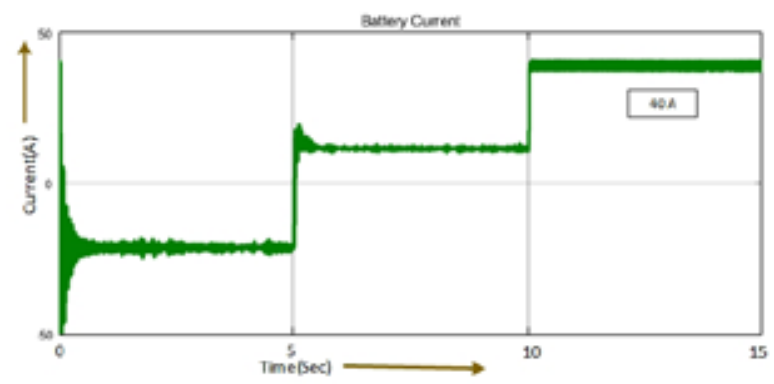

Figure $9(\mathrm{~g})$ : Battery Current

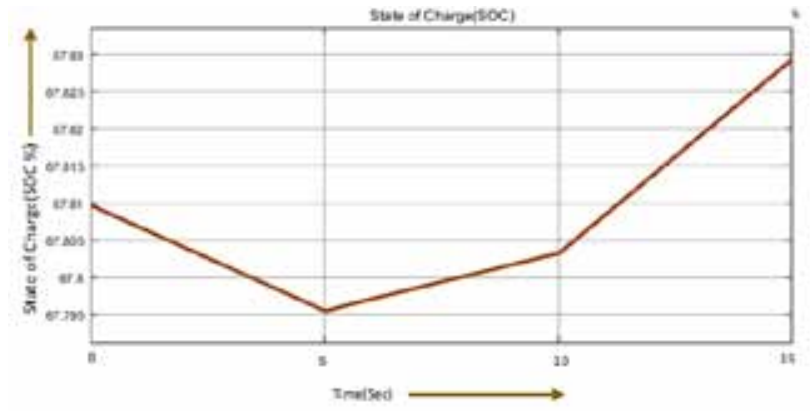

Figure $9(\mathrm{~h})$ : State of Charge (SOC) of Battery

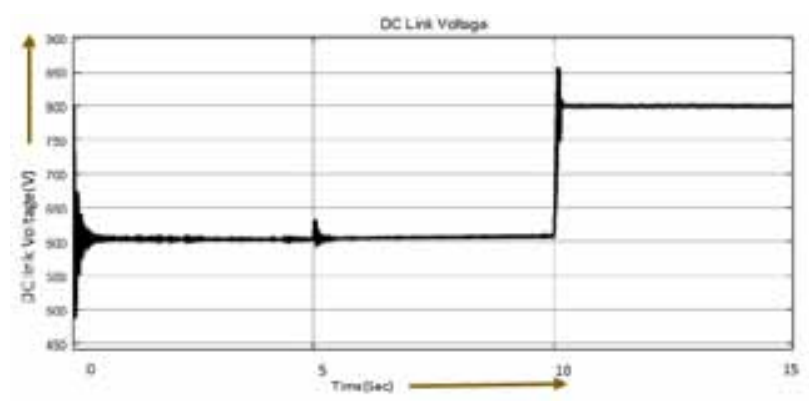

Figure 9 (i): DC link Voltage

Above result is summarized in the following table below:

\begin{tabular}{|c|c|c|c|}
\hline & $0-5 \mathrm{sec}$ & $5-10 \mathrm{sec}$ & $10-15 \mathrm{sec}$ \\
\hline Generated Power & $56.5 \mathrm{~kW}$ & $56.5 \mathrm{~kW}$ & $56.5 \mathrm{~kW}$ \\
\hline $\begin{array}{c}\text { Power Consumed by } \\
\text { load }\end{array}$ & $69.5 \mathrm{~kW}$ & $49.6 \mathrm{~kW}$ & $23.2 \mathrm{~kW}$ \\
\hline $\begin{array}{c}\text { Power Consumed by } \\
\text { battery }\end{array}$ & $-13 \mathrm{~kW}$ & $6.9 \mathrm{~kW}$ & $24.7 \mathrm{~kW}$ \\
\hline $\begin{array}{c}\text { Power dissipated on } \\
\text { dump load }\end{array}$ & $0 \mathrm{~kW}$ & $0 \mathrm{~kW}$ & $8.6 \mathrm{~kW}$ \\
\hline
\end{tabular}

Table 2: Simulation Result

Here, -ve sign put on the power consumed by battery means battery system is supplying the power to the load.

For 5-10 seconds, battery is charged with all excess power and for 10-15 seconds, battery is charged in maximum charging current i.e. $40 \mathrm{~A}$.

To confirm whether the battery is charged with constant voltage or not when SOC $>80 \%$, the model is simulated with load of $20 \mathrm{~kW}$ and SOC $>80 \%$.

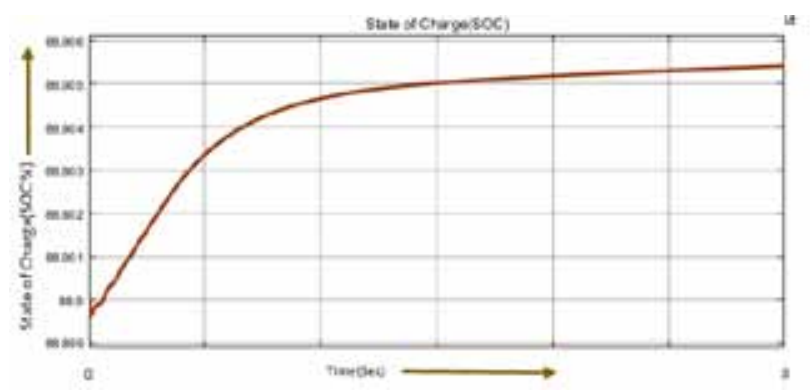

Figure 9 (j): SOC of the Battery

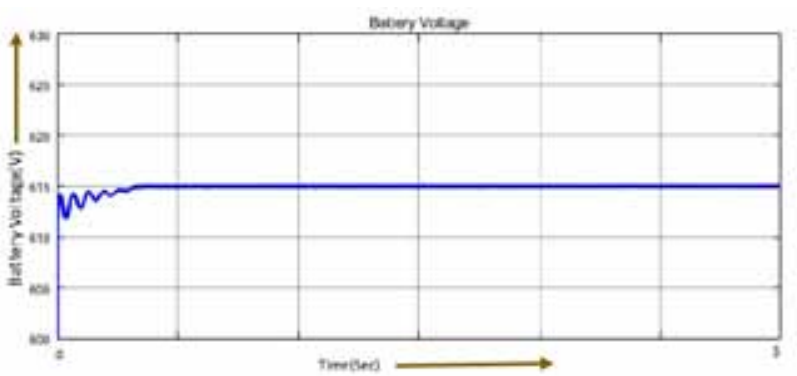

Figure $9(k)$ : Battery Charging Voltage

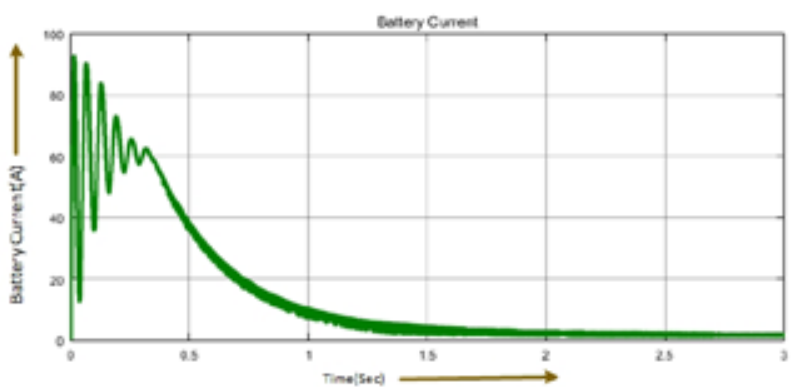

Figure 9 (I): Battery Charging Current 


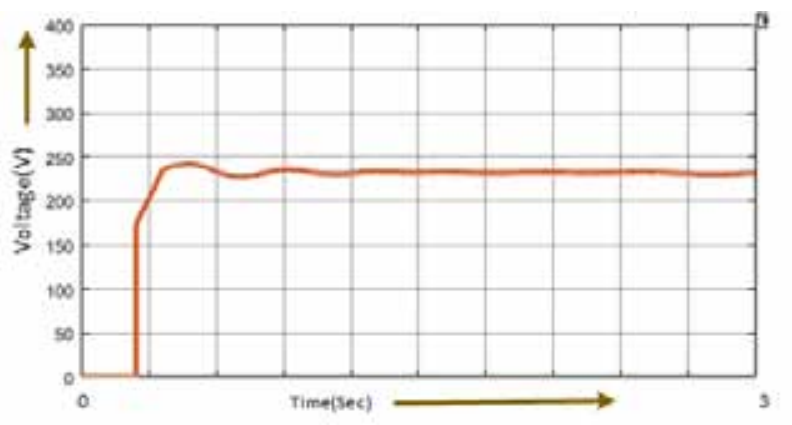

Figure $9(\mathrm{~m})$ : Voltage profile across load

\section{Conclusion}

Battery storage system is incorporated in a conventional ELC based micro-hydro plant. Control strategy for the battery storage system is successfully demonstrated in a Matlab simulation. The battery storage system was able to supply deficient power to the load during peak demand period. Frequency is constantly maintained as $5 \mathrm{OHz}$ without significant change in voltage level. Hence, power was shared among consumer load, dummy load and battery bank as per the requirement.

\section{Acknowledgements}

Authors are indebted to Professor Dr. Indra Man Tamrakar of Tribhuvan University, Institute of Engineering and Mr. Kapil Duwadi of South Dakota State University for their incredible support throughout the research work.

Pradeep Paudel holds Bachelor's Degree in Electrical Engineering from Institute of Engineering, Pulchowk Campus, Tribhuvan University, Nepal. Previously, he served as an assistant lecturer at Kathmandu Engineering College. He is currently an engineer at Nepal Electricity Authority, Nepal.
E-mail: pradeeppaudel324@gmail.com

Shailesh Wasti holds Bachelor's Degree in Electrical Engineering from Kathmandu Engineering College, Tribhuvan University, Kalimati, Nepal. He is currently a lecturer at Kathmandu Engineering College, Kalimati, Nepal.

Corresponding E-mail: Shailesh.wasti@gmail.com

\section{References}

Abusara, M., \& Guerrero, J. (2014). Line-Interactive UPS for Microgrids. IEEE TRANSACTIONS ON INDUSTRIAL ELECTRONICS, 61(3), 1292-1300.

CBS. (2011). NepalLivingStandardSurvey. Kathmandu : CBS.

CBS. (2012). National Population and Housing Census . Kathmandu: CBS.

Gyawali, N., Paudel, B., \& Subedi, B. (2015). Improved Active Power Sharing Strategy for ELC Controlled Synchronous Generators Based Islanded Micro Grid Application. Software, Knowledge, Information Management and Applications (SKIMA).

International Energy Agency . (n.d.). Retrieved from http://www.iea.org/statistics/statisticssearch/

Ranganadh, B., Prasad, A., \& Sreedhar, M. (2013). Modelling And Simulation Of A Hysteresis Band Pulse Width Modulated Current Controller Applied To A Three Phase Voltage Source Inverter By Using Mat lab. International Journal of Advanced Research in Electrical Electronics and Instrumentation Engineering, 2(9), 4378-4387.

Sharma, R. H., \& Awal, R. (2013). Hydropower development in Nepal . Elsevier.

Shrestha, H. M. (1966). Cadastre of hydropower resources. Moscow, USSR: Moscow Power Institute. 